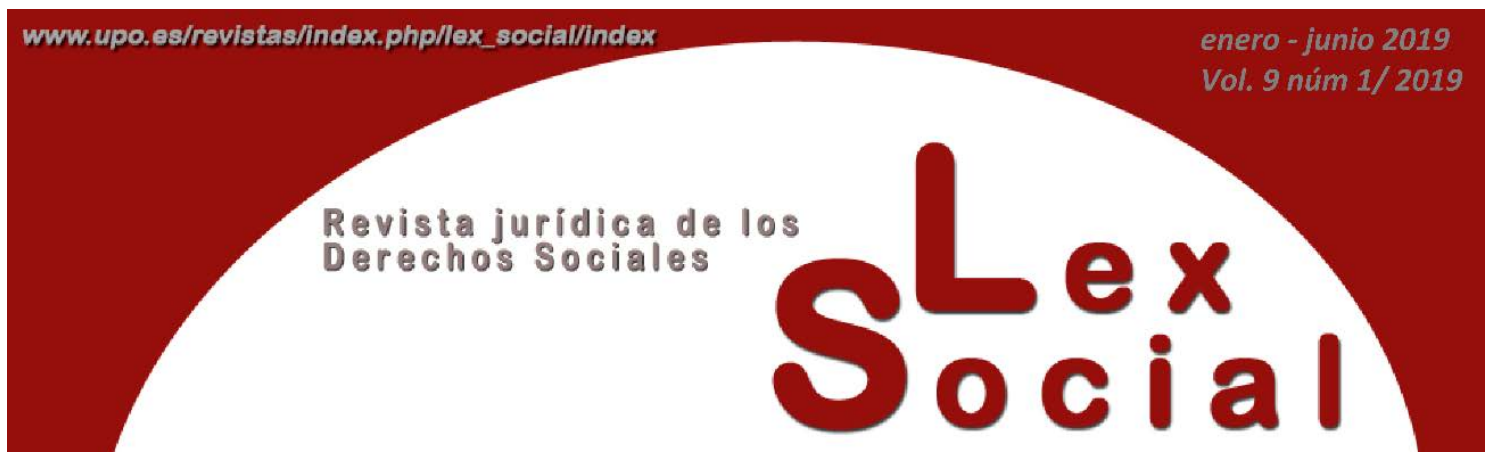

\title{
LA PRUEBA PERICIAL: GESTIÓN Y CONTENIDO EN UN JUICIO DE RESPONSABILIDAD CIVIL POR DAÑO AMBIENTAL
}

\section{THE EXPERT PROOF: MANAGEMENT AND CONTENT IN A JUDGMENT OF CIVIL LIABILITY FOR ENVIRONMENTAL DAMAGE}

RICARDO ANTONIO SALAS ALVARADO

TANIA GARCÍA LÓPEZ1

Artículo recibido el 19 de julio de 2018

Artículo aceptado el 18 de septiembre de 2018

\section{RESUMEN}

La prueba pericial es un medio empleado en los juicios civiles a través del cual se demuestra un daño ocasionado a los bienes o propiedades de una persona. En el caso de un juicio de responsabilidad civil por daños ocasionados al medio ambiente, esta prueba generaría una visión amplia del daño ocasionado.

Respecto al desahogo de la prueba pericial, se expondrá la necesidad procesal de ciertos cambios legales a las disposiciones legales aplicables; con la finalidad de que esta prueba sea una herramienta jurídica de utilidad para el juzgador al momento de resolver un juicio de índole ambiental.

PAlABRAs ClAVE: Responsabilidad civil, daño ambiental, prueba pericial.

\footnotetext{
${ }^{1}$ Tanía García López. Doctora en Derecho por la Universidad de Alcalá, Investigadora SNI nivel II, Investigadora por la Universidad Veracruzana. Ricardo Antonio Salas Alvarado. Doctor en Ciencias Ambientales por la Universidad de Alcalá, investigador por la Universidad Autónoma de San Luis Potosí, México.
} 


\begin{abstract}
The expert evidence is a means used in civil trials through which a damage caused to the property or property of a person is demonstrated. In the case of a civil liability lawsuit for damages caused to the environment, this test would generate a broad view of the damage caused.

Regarding the relief of the expert evidence, the procedural necessity of certain legal changes to the applicable legal provisions will be explained; with the purpose that this test is a legal tool of utility for the judge when resolving a judgment of an environmental nature.
\end{abstract}

KEY WoRDS: Civil liability, environmental damage, expert evidence.

SUMARIO

Introducción

Metodología

1. Ofrecimiento de la prueba pericial

2. Desahogo de la prueba pericial

3. Contenido de la prueba pericial en un juicio civil

4. La prueba pericial ante un daño ambiental

Conclusiones

Bibliografía

\title{
Introducción
}

La prueba pericial es el examen y estudio que realiza el perito sobre el problema encomendado para luego entregar su informe o dictamen pericial con sujeción a lo dispuesto por la ley.

De esta manera, la prueba pericial es "Aquélla que se lleva a efecto mediante el dictamen de peritos”. PINA VARA (1983): 407.

En lo particular, consideramos la definición ofrecida por Mateo Alarcón, que enfatiza la importancia de la utilización de conocimientos científicos o técnicos: 
"El dictamen de las personas versadas en una ciencia, en un arte, en un oficio con el objeto de ilustrar a los tribunales sobre un hecho cuya existencia no puede ser demostrada ni apreciada sino por medio de conocimientos científicos o técnicos; o bien un medio de descubrir la verdad de un hecho, y la forma especial de su demostración deducida de los fenómenos de él o de sus efectos”. MATEOS ALARCON (2001): 242.

La prueba pericial surge del dictamen de los peritos, que son personas llamadas a informar ante el juez o tribunal por razón de sus conocimientos especiales, siempre que sea necesario un dictamen científico, técnico o práctico sobre los hechos en litigio.

Según lo manifestado por Arellano García: "Esa posesión de conocimientos específicos que no todo el mundo posee es lo que da a un sujeto el carácter de perito”. ARRELLANO GARCÍA (1998): 339.

Cabe indicar, como característica, que los conocimientos especializados son temas que por su naturaleza no son de dominio público, ya que se requiere dominar el aspecto técnico.

En lo que se refiere al medio ambiente, el contenido del informe pericial contendrá mínimo tres aspectos:

a. El aspecto técnico: aquí se establecen los parámetros, limites, formulas establecidas en las NOM's.

b. La normatividad ambiental: se debe indicar específicamente las leyes federales, reglamentos federales, normas oficiales mexicanas, leyes ambientales y normas técnicas de la entidad federativa que están vinculadas con el elemento ambiental dañado.

c. La metodología del peritaje: es este rubro, es importante indicar la metodología que se siguió para desarrollar el informe pericial.

\section{Metodología}

En este trabajo se sigue el método descriptivo, ya que el objetivo general fue determinar el momento procesal adecuado o idóneo para ofrecer la prueba pericial en un juicio civil para reparar un daño ambiental; en este sentido, se consideraron las características que tiene el daño ambiental y los efectos adversos que puede ocasionar un daño ambiental, por ejemplo sobre la salud de las personas.

El tema abordado surge del ejercicio profesional como abogado litigante, permitiendo obtener la información requerida en forma directa a través de la iniciación y seguimiento de los juicios hasta la obtención de una sentencia definitiva. En estos se observó la forma en que se ofreció la prueba pericial para que tal probanza tuviera valor y generará consecuencias legales. 


\section{Ofrecimiento de la prueba pericial}

La prueba pericial es idónea en un juicio para conocer o apreciar algún hecho de influencia en el pleito, de manera que son necesarios y convenientes los conocimientos científicos, artísticos o prácticos.

Los medios de prueba del Derecho Procesal Civil son los siguientes:

I.- La confesión.

II.- Los documentos públicos.

III.- Los documentos privados.

IV.- Los dictámenes periciales.

V.- El reconocimiento o inspección judicial.

VI.- Los testigos.

VII.- Las fotografías, escritos y notas taquigráficas, y, en general, todos aquellos elementos aportados por los descubrimientos de la ciencia, $\mathrm{y}$

VIII.- Las presunciones.

Los medios de prueba "Tienen como finalidad el producir un estado de certidumbre en la mente de una o varias personas respecto de la existencia o inexistencia de un hecho, de la verdad o falsedad de una proposición”. PALLARES (1984): 657.

Como indica Hutchinson "No hace falta mayor imaginación para comprender la enorme importancia que la prueba tiene en la vida jurídica. Sin ella los derechos subjetivos de una persona serían simples apariencias, sin solidez ni eficacia alguna”. HUTCHINSON (1999): 193.

El procedimiento civil reviste de etapas procesales que se deben cumplir una por una de acuerdo a determinados términos o plazos, la doctrina procesal civil indica que no se pueden renunciar a las etapas. En forma general podemos indicar que las etapas procesales dentro de un juicio ordinario civil son:

1. Demanda.

2. Emplazamiento.

3. Contestación de demanda.

4. Ofrecimiento de pruebas.

5. Desahogo de pruebas.

6. Alegatos.

7. Sentencia.

En el caso concreto de la prueba pericial, ésta debe plantearse de acuerdo a la normatividad procesal civil en la etapa conocida como "ofrecimiento de pruebas". Cabe indicar que actualmente en la práctica o litigio de un asunto civil (cualquiera que sea la 
acción interpuesta), desde el momento en el que se interpone la demanda hasta la etapa de ofrecimiento de pruebas pueden transcurrir de dos a cuatro meses, aproximadamente, por las siguientes razones:

1. Tiempo en que se radica la demanda (una o dos semanas).

2. Efectuar el emplazamiento (una o dos semanas después de que se dicte el auto de radicación, de acuerdo a la agenda del actuario y a la carga de trabajo del juzgado). Esto en el caso que se localice al demandado en la primera búsqueda que se efectúe, en caso contrario se tendría que hacer uso de horas inhábiles, solicitar edictos, dejar citatorios, etcétera, lo cual implicaría un tiempo aproximado de uno a dos meses.

3. El tiempo laboral del órgano jurisdiccional toda vez que sólo hay actividades de lunes a viernes, de 8:00 a 15:00 horas. No inician, corren ni finalizan los términos en días y horas inhábiles (sábados y domingos), días festivos de acuerdo a la Ley Federal del Trabajo.

4. Para transitar de una etapa procesa a otra, es a petición de parte, es decir, las partes deben solicitar que se pase a la siguiente etapa procesal. La respuesta donde se decrete la subsecuente etapa se da a conocer en una o dos semanas aproximadamente.

5. Por excepciones o defensas planteadas en la contestación de demanda, lo que originaría que la etapa de ofrecimiento de pruebas no se decrete al concluir el término para contestar la demanda, toda vez, hay que recordar que existen excepciones que suspenden el juicio en lo principal y no se puede continuar hasta que exista una sentencia interlocutoria que las resuelva. El tiempo estimado para notificar y resolver sobre las excepciones es de entre uno a dos meses.

Por otro lado, al tratarse de un juicio ordinario civil las partes tienen plenamente identificada la clase y contenido de la prueba pericial que les va a servir para probar su acción o excepción (según sea el caso).

El procedimiento para el ofrecimiento de la prueba pericial, como requisito legal y como orientación para las partes en el proceso, está claro y expresamente establecido en el artículo 143 del Código Federal de Procedimientos Civiles; dicho artículo señala que "La prueba pericial tendrá lugar en las cuestiones de un negocio relativas a alguna ciencia o arte, y en los casos en que expresamente lo prevenga la ley”. CÓDIGO FEDERAL DE PROCEDIMIENTOS CIVILES (1943): 22.

Por ello, en toda controversia judicial, que por su naturaleza requiera de la opinión especializada de una persona sobre un determinado tema, se requiere que tal probanza y el dictamen pericial que se emita al respecto, incluyan ciertas cuestiones que no dejen dudas en el criterio del juzgador.

La prueba pericial, por su contexto y alcance, es un medio de prueba apropiado para acreditar un daño ambiental; es decir, se puede evidenciar una situación específica y 
lograr que la mente la perciba con la misma claridad con que los ojos ven las cosas materiales.

Es importante que el juzgador considere la prueba pericial en un juicio civil por responsabilidad ambiental en base a las siguientes razones:

I. Para acortar el tiempo de su ofrecimiento, es decir, sin esperar hasta el periodo de ofrecimiento de pruebas, tal como viene contemplado en la normatividad procesal civil.

II. El daño ambiental está intacto o en su defecto incrementándose.

III. El informe pericial debe realizarse con más prontitud y contar con las conclusiones a la brevedad ya que depende del elemento ambiental dañado donde el estudio técnico requiere de tiempo para demostrar resultados.

Esta situaciones se deben a la naturaleza del juicio y al bien jurídico protegido que es el ambiente: la existencia y por consiguiente la reparación de un daño ambiental que puede ocasionar alteraciones en la vida y salud de personas en un lugar determinado y que de acuerdo a sus características puede repercutir a otras personas ajenas y diferentes al lugar donde se originó el daño ambiental.

\section{Desahogo de la prueba pericial}

El Código Federal de Procedimientos Civiles establece en su artículo 337 lo relativo al desahogo de la prueba pericial, indicando al respecto: "Transcurrido el término para contestar la demanda o la reconvención, en su caso, el tribunal abrirá el juicio a prueba, por un término de treinta días”. CÓDIGO FEDERAL DE PROCEDIMIENTOS CIVILES (1943): 48.

Solamente se van a desahogar aquellos medios de prueba que fueron ofrecidos en la etapa procesal correspondiente.

Por su naturaleza, los documentos privados y públicos no ameritan fecha y hora para su desahogo. Las pruebas que sí ameritan día y hora para su desahogo son: la confesión, los dictámenes periciales, el reconocimiento o inspección judicial y los testigos.

Durante el plazo de treinta días se recibe la declaración de los testigos, se presentan las partes a contestar las posiciones derivadas de las confesionales y se visita el lugar donde se va a efectuar el reconocimiento o inspección judicial.

En el caso de la prueba pericial durante ese término de treinta días se recaba información, se elabora y. por último, se presenta el informe pericial, salvo casos concretos por la naturaleza del peritaje se hace saber al juez del impedimento o motivo 
de que no se puede presentar el informe durante el lapso concedido y se precisa un término adicional.

\section{Contenido de la prueba pericial en un juicio civil}

La prueba pericial se le solicita al perito. Se trata, según la doctrina de "Un criterio, una apreciación realizada mediante la invocación de la ciencia”. VIZCARRA DAVALOS (2003): 235.

Esta valoración recae sobre los hechos y no sobre el ámbito jurídico; al respecto De Santo indica: "El peritaje debe versar sobre hechos y no sobre cuestiones jurídicas, ni sobre exposiciones abstractas que no influyan en la comprobación, la apreciación o la interpretación de los hechos del proceso” DE SANTO (2002): 26.

De esta forma, los hechos controvertidos, materia de peritaje, son la evaluación del daño ambiental existente y el grado de afectación que los elementos ambientales tienen en ese momento.

Asimismo, cabe mencionar que, actualmente, no existe una metodología determinada y general que sirva como modelo al momento de elaborar un dictamen pericial en materia ambiental.

Cada ciencia plantea y desarrolla una serie de pasos en la elaboración y conclusiones de dictámenes periciales cuando son requeridos en juicios civiles, fiscales o penales, según el tema que se pretenda demostrar.

Cabe indicar que los requerimientos del informe pericial deben seguir una argumentación propia, es decir, un proceso cognitivo especializado que se realiza mediante la articulación de inferencias diagnósticas concatenadas con los datos de la causa judicial, coherentes y exhaustivas, basadas en la razón suficiente y con conocimiento idóneo sobre el caso que se trata para llegar, así, a conclusiones fundadas.

\section{La prueba pericial ante un daño ambiental}

Al tratarse de un juicio ordinario civil para reparar un daño ambiental, existen cuestiones que rompen con lo establecido, toda vez que la materia ambiental contiene situaciones que deben considerarse como primordiales.

La materia ambiental está revestida de estándares científicos que son fundamentales en el cumplimiento de lo señalado en la normatividad ambiental y en ocasiones un daño ambiental puede tener su origen en una deficiente administración en materia de seguridad y ambiental por parte de una persona física o moral. 
En un juicio por daño ambiental el juez, al momento de valorar las pruebas, debe tener en cuenta el principio actori incumbit probatio que establece: "Exige al juez que la falta, el daño y el perjuicio serán establecidos con certeza, pues no puede contentarse con indicios; no se puede aceptar comprometer la responsabilidad del demandado sino cuando la prueba lo acredite”. HUTCHINSON (1999): 194.

Mediante esta prueba, cuyo contenido es técnico, se aporta información relevante y concisa para determinar si se generó o no un daño ambiental, al tiempo que pueden mostrarse planteamientos, conclusiones y resultados que, según la apreciación del juzgador, se consideren como hechos ciertos.

En un juicio de responsabilidad civil para reparar un daño ambiental, debe considerarse y plantearse que, en materia ambiental, se cuenta con un caudal científico (técnico) en su accionar, de modo que no se limita a una pura interpretación de la norma jurídica.

De tal forma el juzgador, a través del desahogo de la prueba pericial, obtiene una certeza real del daño ambiental ocasionado y, a partir de entonces, no debe considerarlo como un indicio. Aun cuando sea la única prueba que después de su valoración se considere plena.

Cabe indicar que en un juicio por daño ambiental, ambas partes (actor y demandado), al momento de ofrecer la prueba pericial, no tienen trazado el contenido y alcance de dicha probanza.

A la parte actora le interesa que este medio de prueba exponga con precisión y claridad el daño que se ha generado en uno o varios de los elementos ambientales, cuál es el que presenta más afectación y qué factores generaron el daño ambiental.

Por otro lado, el objetivo de la parte demandada es acreditar mediante la prueba pericial que el referido daño inferido al ambiente no es producto de sus operaciones, del uso de determinadas sustancias químicas empleadas en sus procesos productivos, almacenes, maquinaria o equipo.

En este sentido, debe probarse el nexo de causalidad entre el daño y la conducta imputada, por lo que opinamos que el desahogo de la prueba pericial y sus conclusiones pueden acreditar tal situación y con ello cumplir con lo establecido en la Ley Federal de Responsabilidad Ambiental en su artículo 36 segundo párrafo que manifiesta:

"El nexo de causalidad entre el daño ocasionado y la conducta imputada al demandado debe probarse en la sustanciación del juicio. El juez considerará en su valoración la naturaleza intrínseca de la conducta y la forma en que se ha desarrollado para generar o causar el daño”. LEY FEDERAL DE RESPONSABILIDAD AMBIENTAL (2013): 10. 
Por lo que, consideramos pertinente hacer uso de herramientas empleadas en la industria, ya que son instrumentos o metodologías que aportarían un valor importante en la identificación de un daño ambiental a través del informe pericial.

Lo anterior debe elaborarlo, formularlo, plantearlo y exhibirlo el perito; ya que el perito debe contar con la mayor cantidad de formación y preparación para elaborar por su cuenta el contexto completo del peritaje por lo que diferimos de lo expresado por De Santo:

"El perito, para el mejor cumplimiento de su cometido, puede consultar el caso con otros expertos, obtener conceptos u opiniones que lo asesoren, solicitar la preparación de planos o croquis aclarativos de su dictamen y según sus directivas, siempre que luego adopte y explique su personal conclusión”. DE SANTO (2002): 60.

Así, el peritaje debe ser un instrumento técnico-jurídico que sirva como medio de enlace entre los hechos y lo que se pretende demostrar, por lo que su contenido abarcaría temas específicos de valoración, los instrumentos, la determinación de la causa, los efectos de los hechos y la metodología para su desarrollo.

En este tipo de peritajes, como consecuencia de su contenido, el objeto de estudio está impregnado de cuestiones técnicas y de valores numéricos insertos en las normas oficiales mexicanas en materia ambiental y de seguridad.

El peritaje ambiental, en su aspecto técnico, debe ser claro en sus conclusiones, que resulten inequívocas y que, por lo tanto, el juez pueda hacerlas suyas en la sentencia definitiva que vaya a dictar.

Otro aspecto importante del peritaje ambiental es que no deben existir limitaciones en la exposición de los conceptos, motivos y conclusiones formulados por parte del perito en su informe. En caso de que un dictamen que careciera de lo anterior, no tendría valor probatorio pleno al dictarse sentencia definitiva.

Asimismo, si el perito no resultase convincente en la formulación de sus conclusiones al emitir su informe pericial, el daño ambiental no quedaría identificado y demostrado al juzgador, por consiguiente no le sería útil al momento de dictar la sentencia definitiva en un juicio de responsabilidad para reparar un daño ambiental.

El informe pericial debe limitarse a los puntos planteados a los peritos en el momento de ofrecerse esta prueba, abarcando en el dictamen cuestiones que los peritos consideren como sus antecedentes, causas o fundamentos necesarios.

De tal manera, el informe pericial ambiental, debe tener las siguientes características:

1. Debe abordar lenguaje técnico, jurídico y general. No se puede delimitar a una sola disciplina científica. 
2. Su lenguaje debe ser sencillo y científico, para que lo comprendan el juez y la parte actora, ya que el demandado cuenta con personal que maneja e interpreta el lenguaje científico de la ingeniería y la química. Sin embargo, es necesario destacar que no todas las partes que intervienen en un juicio de responsabilidad civil para reparar un daño ambiental tienen el mismo nivel de conocimientos técnicos o legales.

3. Debe contar con una estructura lógica y específica que sirva de apoyo a todo peritaje ambiental, donde únicamente se cambie la evaluación y valoración del elemento o elementos ambientales afectados; es decir, que exista una estructura única y que solo varíe la forma de evaluar los elementos ambientales afectados.

4. No debe dejar dudas en su conclusión o conclusiones, especificando plenamente la existencia o inexistencia del daño ambiental.

En este punto es importante destacar que si el dictamen versa sobre puntos ajenos y diferentes, carecerá de eficacia probatoria, porque no se concentra en lo que se le requirió al perito antes de efectuarse el peritaje.

En este sentido, el juzgador puede solicitar a la parte demandada información pertinente de los procesos productivos, relación de maquinaria y equipo, inventario de insumos, además de la cédula de operación anual (COA) que haya emitido a SEMARNAT o al respectivo instituto ambiental estatal.

Para ello, puede fundamentar su auto en el artículo 34 párrafo primero de la Ley Federal de Responsabilidad Ambiental que señala: “El órgano jurisdiccional podrá allegarse oficiosamente los medios de prueba que considere necesarios, sin más limitaciones que las establecidas en la ley”. LEY FEDERAL DE RESPONSABILIDAD AMBIENTAL (2013): 10.

En este sentido Cabanellas señala

"Es la facultad de los jueces o tribunales para interponer su autoridad espontáneamente, sin requerimiento o instancia de parte, tanto en las causas civiles, donde tal potestad es más restringida, como en el proceso penal, donde el interés público autoriza mayores atribuciones”. CABANELLAS (1981): 666.

Por otro lado, en la mayor parte de los asuntos civiles se nombra a dos peritos, uno por cada parte (actor y demandado). En caso de conflicto sobre lo expresado en el dictamen pericial se plantea la pertinencia de nombrar un tercer perito, cuya designación es por parte del juzgador.

En atención a tal circunstancia, no consideramos pertinente, desde el punto de vista legal y ambiental, la intervención de un tercer perito por las siguientes razones:

1. No habría tiempo, desde que se nombra al tercer perito, para realizar las evaluaciones, análisis y conclusiones del informe pericial. 
2. Las condiciones del daño pueden llegar a variar, generando incertidumbre en la existencia del daño ambiental.

3. El daño ambiental puede extenderse a otros elementos ambientales.

4. La falta de peritos ambientales, pues actualmente no existen un gran número de tales expertos.

Como el peritaje versa sobre un daño ambiental debe aplicarse el artículo 148 tercer párrafo del Código Federal de Procedimientos Civiles que expresa que: "En cualquier caso se fijará a los peritos un término prudente para que presenten su dictamen”.

Es necesario que el tiempo de presentación de los informes periciales se encuentre agregado en autos antes del auto que cite para sentencia definitiva el juicio.

El juzgador, al concluir el periodo otorgado a los peritos para que exhiban el dictamen pericial, sin que se haya presentado en el juicio de responsabilidad para reparar un daño ambiental, debería establecer una sanción económica.

\section{Conclusiones}

Primera. Es importante que la prueba pericial aparezca en un juicio para reparar un daño ambiental en dos casos concretos:

1. El juzgador debería decretar de oficio la prueba pericial mediante una determinación judicial, es decir, en el auto de radicación donde admite la demanda respectiva, aun cuando no tenga la certeza jurídica de que las partes la vayan a ofrecer en la etapa procesal correspondiente.

2. El ofrecimiento de la prueba pericial deba plantearse por el actor en su escrito de demanda y por el demandado en su escrito de contestación de la misma.

Segunda. El momento idóneo para el desahogo de la prueba pericial en un juicio de responsabilidad para reparar un daño ambiental debe ser:

1. El del vencimiento del término de contestación de la demanda.

Este planteamiento obedece a que el desahogo de la prueba pericial empiece a ejecutarse a los tres días después de vencido el término de contestación; de lo contrario, si transcurre más tiempo, el demandado tendrá la oportunidad de planear actividades con la finalidad de remediar o dar mantenimiento a patios, tuberías, maquinaria o equipos.

2. Tres días después de efectuarse el emplazamiento a la contienda judicial.

En cualquiera de los dos supuestos señalados el juzgador en el auto de radicación establecerá fecha y hora para desahogar la prueba pericial fundamentándolo en el artículo 148 primer párrafo del Código Federal de Procedimientos Civiles que indica: "El tribunal señalará lugar, día y hora para que la diligencia se practique, si él debe presidirla”. 
CÓDIGO FEDERAL DE PROCEDIMIENTOS CIVILES (1943): 23. Con ello se garantizaría el derecho de audiencia del demandado.

En ambos supuestos de desahogo de la prueba pericial, el juez debe nombrar al perito y notificarle el auto de radicación para que acepte el cargo conferido y esté pendiente de la evolución del proceso civil.

Tercera. El juez debe fijar fecha y hora para celebrar una audiencia, la cual se verificará a los cinco días de la recepción del informe pericial; lo anterior, para que el perito pueda dar al juzgador las explicaciones detalladas y precisas o aclaraciones que se requieran con respecto al peritaje.

Esta audiencia se establecerá con la finalidad de que el juez formule los cuestionamientos pertinentes a los peritos para clarificar la descripción física, de maquinaria, de sustancias químicas, cuestiones técnicas o de documentos agregados al peritaje, con respecto de las cuales exista alguna duda.

Cuarta. En los juicios de responsabilidad civil para reparar un daño ambiental, todo dictamen pericial debe contener lo planteado en la siguiente tabla:

\section{Tabla 1:}

\section{Contenido de un informe pericial por daño ambiental}

\begin{tabular}{|c|c|}
\hline Ítems generales & Ítems específicos \\
\hline \multirow{5}{*}{$\begin{array}{l}\text { Descripción de la persona } \\
\text { (física o jurídica) a quien se } \\
\text { le imputa el daño } \\
\text { ambiental. }\end{array}$} & Razón social o denominación / nombre. \\
\hline & Domicilio. \\
\hline & Nombres de los colindantes. \\
\hline & Actividad preponderante. \\
\hline & Descripción de sus instalaciones, procesos e insumos. \\
\hline \multirow{4}{*}{$\begin{array}{l}\text { Descripción del elemento o } \\
\text { elementos ambientales y } \\
\text { materia de examen o } \\
\text { estudio (forma y estado en } \\
\text { que se encontraba al } \\
\text { momento de hacer el } \\
\text { peritaje). }\end{array}$} & Qué elementos son los afectados. \\
\hline & Cuál refiere más daño y por qué. \\
\hline & Dónde se localizan los elementos ambientales dañados. \\
\hline & $\begin{array}{l}\text { En qué parte (físicamente) se localiza el daño. } \\
\text { Evidencia fotográfica del daño ambiental (si es } \\
\text { procedente, de acuerdo al elemento ambiental), así como }\end{array}$ \\
\hline
\end{tabular}


Precisión de los puntos del peritaje ambiental.

Relación detallada de todas las operaciones.

Descripción y desarrollo de metodología

Resultado de la maquinaria o equipo e instalaciones. En general del medio ambiente de trabajo que tiene el demandado.

Se formularán o precisarán los puntos sobre qué debe versar el peritaje.

Describir cada una de las maquinarias o equipos existentes en el lugar (haciendo referencia a la capacidad operativa).

Qué materia prima utiliza y cómo se almacena.

Qué sustancia química emplea (dónde se almacena temporalmente antes y después de su uso).

Qué tipo de residuos peligrosos son generados en cada máquina y equipo (describiendo la forma de almacenamiento, tipo de contenedores, tiempo de almacenamiento y descripción de las condiciones de seguridad de los almacenes).

Si genera calor, ruido o tiene fugas de aceite o agua, y si las mangueras y sistema eléctrico funcionan adecuadamente.

Layout (planos) de la planta donde se ubican la maquinaria, el equipo, almacenes (de residuos peligrosos y de sustancias químicas), recipientes sujetos a presión, contenedores de sustancias altamente peligrosas.

En primer término, desarrollar diagramas de Pareto y posteriormente la metodología de la estratificación.

Con la información que arrojó la estratificación, realizar diagramas de Ishikawa.

En su defecto, hacer uso de diversa metodología o de un programa electrónico para evaluar el daño ambiental; se debe precisar el alcance y resultado de dicho programa informático.

Cotejar datos con los estándares de las normas oficiales mexicanas en materia ambiental (ruido, atmósfera, residuos peligrosos, suelo y agua).

Cotejar los datos con la legislación local (de acuerdo al lugar donde se generó el daño), para materia como los residuos industriales no peligrosos.

Cotejar datos de los estándares de las normas oficiales mexicanas en materia de seguridad e higiene de la maquinaria, equipo, sustancias químicas e instalaciones. Manifestar la existencia o no del daño a los elementos ambientales. 
Señalar el grado de afectación de mayor a menor de acuerdo con los elementos ambientales dañados.

Indicar la procedencia o no de la remediación de acuerdo con el elemento ambiental afectado y tiempo de recuperación.

Cotejo de los estudios técnicos del demandado con el dictamen pericial.

Recomendaciones.

De acuerdo con los elementos ambientales dañados.

Para desarrollar las herramientas de estratificación, diagrama de Pareto y diagrama de Ishikawa, se requiere que el perito conozca y desarrolle estas metodologías en forma plena y eficaz para que el resultado brinde una certeza de valoración del daño ambiental ocasionado y manifieste el grado de afectación correspondiente a los elementos ambientales.

Quinta. En la propuesta del formato del peritaje deberían agregarse diversos planos de las instalaciones, maquinaria o equipo de la persona física o moral, donde se contemple la siguiente información:

1. Superficie de la parte demandada.

2. La ubicación de la maquinaria o equipo que genera el daño ambiental.

3. Los almacenes de materia prima, de residuos peligrosos y de los residuos no peligrosos.

4. Los recipientes sujetos a presión y tanques de almacenamiento o de los ductos de suministro de sustancias químicas.

\section{Bibliografía}

Arrellano, C. (1998). Derecho Procesal Civil. México: Porrua.

Cabanellas, G. (1981). Diccionario Enciclopédico de Derecho Usual. Argentina: Heliasta.

Código Federal de Procedimientos Civiles (1943, 24 febrero). (en línea). México: Camara de Diputados $H$. Congreso de la Unión. Disponible en: http://www.diputados.gob.mx/LeyesBiblio/pdf/6.pdf Diario Oficial de la Federación. (2017, 20 septiembre).

De Santo, V. (2002). El Proceso Civil tomo VII Prueba de Perito, Reconocimiento Judicial. Argentina: Universidad.

Hutchinson, T. (1999). Daño Ambiental Tomo II. Argentina: Culzoni.

Ley Federal de Responsabilidad Ambiental (2013, 07 junio). (en línea). México: Camara de Diputados H. Congreso de la Unión. Disponible en: 
http://www.diputados.gob.mx/LeyesBiblio/pdf/6.pdf Diario Oficial de la Federación. (2017, 20 agosto).

Mateos, M. (2001). Las Pruebas en materia civil, mercantil y federal. México: Porrua.

Pallares, E. (1984). Diccionario de Derecho Procesal Civil. México: Porrua.

Pina Vara, R. (1983). Diccionario de Derecho. México: Porrua.

Vizcarra, J. (2003). Teoría General del Proceso. México: Porrua. 